\title{
Pain in Women: A Perspective Review on a Relevant Clinical Issue that Deserves Prioritization
}

Roberto Casale (D) - Fabiola Atzeni · Laura Bazzichi · Giovanna Beretta •

Elisabetta Costantini $\cdot$ Paola Sacerdote $\cdot$ Cristina Tassorelli

Received: September 9, 2020 / Accepted: February 8, 2021 / Published online: March 15, 2021

(C) The Author(s) 2021

\section{ABSTRACT}

Introduction: Gender equity and gender medicine are opportunities not to be missed, and this Expert Group Opinion Paper on pain in women aims to review the treatment of pain conditions mainly affecting women, as well as the fundamental aspects of the different clinical response to drug treatment between the genders, and what can be done for gender-specific rehabilitation.

R. Casale $(\bowtie)$

OPUSmedica, PC\&R, Persons, Care \& Research

Network, Piacenza, Italy

e-mail: robertocasale@opusmedica.org

F. Atzeni

Rheumatology Unit, Department of Clinical and Experimental Medicine, University of Messina, Messina, Italy

\section{Bazzichi}

Rheumatology Unit, Department of Clinical and Experimental Medicine, A.O.U.P., Pisa, Italy

G. Beretta

Rehabilitation Medicine and Neurorehabilitation, ASST Grande Ospedale Metropolitano Niguarda, Milan, Italy

E. Costantini

Andrological and Urological Clinic, Terni Hospital, Terni, Italy
Methods: Perspective review.

Results: Genotypic and phenotypic differences in pain between the sexes are conditioned by anatomical, physiological, neural, hormonal, psychological, social, and cultural factors, such as the response to pharmacological treatment to control pain. The examination of these factors shows that women are affected by pain diseases more frequently and severely than men and that they report pain more frequently and with a lower pain threshold than men. Some forms of pain are inherently related to gender

\section{E. Costantini}

Department of Surgical and Biomedical Science, University of Perugia, Perugia, Italy

\section{P. Sacerdote}

Department of Pharmacological and Biomolecular Sciences, Università Degli Studi Di Milano, Milan, Italy

C. Tassorelli

Headache, Science and Neurorehabilitation Centre, IRCCS Mondino Foundation, Pavia, Italy

\section{Tassorelli}

Department of Brain and Behavioural Sciences, University of Pavia, Pavia, Italy 
differences, such as pain related to the genitourinary system. However, other forms of chronic pain are seen more frequently in women than men, such as migraine, rheumatological, and musculoskeletal pain, in particular fibromyalgia.

Discussion: Research is needed into the pathophysiological basis for gender differences in the generation of acute pain and maintenance of chronic pain, including the factors that put women at higher risk for developing chronic pain. In addition, different specialties need to collaborate to develop gender-related diagnostic and therapeutic guidelines, and healthcare professionals need to upskill themselves in the appropriate management of pain using existing diagnostic tools and therapeutic options.

Keywords: Dysfunctional syndromes; Gender; Pain; Women

\section{Key Summary Points}

Men and women exhibit differences in the epidemiology and natural history of certain diseases, including chronic painrelated pathologies.

These genotypic and phenotypic differences in pain between the sexes are multifactorial and can be caused by anatomical, physiological, neural, hormonal, psychological, social, and cultural factors.

Some forms of chronic pain seen more frequently in women than men include migraine, rheumatoid arthritis, fibromyalgia, and bladder pain syndrome.

To date, no pharmacological options for the management of chronic pain have been specifically developed for women, and the treatment of chronic pain is largely managed using drugs that were initially developed for other diseases and have limited effectiveness and problematic tolerability.

\section{DIGITAL FEATURES}

This article is published with digital features, including a summary slide, to facilitate understanding of the article. To view digital features for this article go to https://doi.org/10.6084/ m9.figshare.13721599.

\section{INTRODUCTION}

Clinical data indicate that men and women exhibit differences in the epidemiology and natural history of certain diseases, including chronic pain-related pathologies [1]. Research on the relationship between gender and pain has increased in recent years, covering a broad range of investigations, including preclinical studies on sex differences in pain, gender differences in pain perception and endogenous pain modulation in healthy individuals, and clinical and epidemiological investigations of gender differences in pain prevalence and response to pain treatments. Several hypotheses have been formulated to explain this gender imbalance, including sex hormones and reproductive and genetic factors. However, in most cases, the evidence is conflicting, so none of the current hypotheses have enough evidential support to impact the clinical management of pain. Indeed, a number of carefully controlled experiments on sex differences in human pain perception have been carried out in the past decades, with results suggesting that women may have a lower threshold for pain, thus being more exposed to perceive pain, or have less tolerance for intense stimuli [2-4]. However, researchers failed to identify any anatomical or physiological factors in the so-called pain matrix to explain such differences.

Sex differences in pain response have been extensively reported, and these are related to several factors, including the type of the stimulus (heat/cold, electrical, pressure, and ischemic stimulation) and the area (size and site) of the body where the stimulus is applied [5-7]. Moreover, factors other than stimulus characteristics appear to be relevant in generating differences in pain perception, for example, the sex of the experimenter and their 
"attractiveness" and the settings in which the experiment was carried out [8]. Other variables, such as concomitant pathologies (e.g. diabetes, overweight), as well as the age of the subject, may also be relevant in determining differences in pain perception between sexes [9].

Age, body weight, and comorbid mental disorders also significantly modify the efficacy of pain treatment with opioids. A recent metaanalysis suggests that men and women may differ in the response to opioids for pain relief, but the data are inconsistent [10]. In addition to the aforementioned factors, the results of studies into opioid response are also influenced by the type of opioids, route of administration, and indication for pain management, but the role of these factors is not usually evaluated [10]. Therefore, it is impossible to draw a clear-cut conclusion on differences in opioid response between the sexes. In addition, the etiology of sexual dimorphism in pain and opioid response has not been fully elucidated, although there is "plausible" cross-talk between sex hormones and neuroimmunological signaling involving toll-like and purinergic receptors [11].

Menstrual phases and reproductive status have been shown to affect pain ratings in women [12]; therefore, the impact of hormones on pain perception may help to explain the clear predominance of women over men in the prevalence of many chronic pain syndromes [9]. The effects of gonadal hormones on pain perception has been tested in various clinical settings, including in transgender individuals receiving cross-sex hormones, as these individuals may represent a model for studying the relationship between sex hormones and pain. Interestingly, during hormone administration, men transitioning to women experienced mainly headaches and breast and musculoskeletal pain [13], resembling the real-world, sex-related epidemiological distribution of chronic pain (see the contributions on migraine, rheumatoid arthritis, and fibromyalgia in this paper). However, this elegant study in transgender individuals failed to demonstrate any central or peripheral action of sex steroids on the pain matrix, and not all subjects developed any form of pain [13], suggesting that sex steroids alone are not enough to explain sex differences in pain propensity.
Given all of these interacting variables, including the psychosocial influences on pain perception [14], it is not currently possible to draw clear conclusions on the peripheral or central nature of sex differences in pain perception. However, studies on specific disorders in which pain is a prominent component may provide additional useful clinical information on the nature of sex differences in pain. Several attempts have been made to group recurrent pain according to gender prevalence. The original and updated Classification of Chronic Pain [9] provides information about sex prevalence for about 85 chronic pain conditions, of which migraine, myofascial pain (including fibromyalgia), and rheumatic pain show the most marked sex differences in prevalence (Table 1) [9, 15-17].

The aim of this multidisciplinary Expert Group Opinion Paper on pain in women is to discuss some pivotal basic science as well as clinical aspects of the broader problem of pain control in women, highlighting particular unmet needs in some of the most representative gender-related pain conditions, including migraine, fibromyalgia and myofascial pain, rheumatic pain, and pelvic pain. We also provide a brief historical perspective on gender medicine and its development in Italy, as well as describing gender-specific approaches to rehabilitation, as this is arguably one of the most neglected aspects of gender medicine.

\section{A Historical Perspective on Gender Equity and Gender Medicine}

The American journalist Barbara Seaman started the women's health movement in the 1950s [18], and in the ensuing decades many steps have been taken towards recognizing and understanding gender-specific medicine. The United States was among the first countries to promote gender-specific medicine through the National Institutes of Health (NIH) and the Food and Drug Administration (FDA) in the 1990s [19]. In Europe, projects were launched and funded by the European community to implement gender in biomedicine and health research and to improve the gender-related 
Table 1 Pain conditions showing differential prevalence between men and women [9, 15-17]

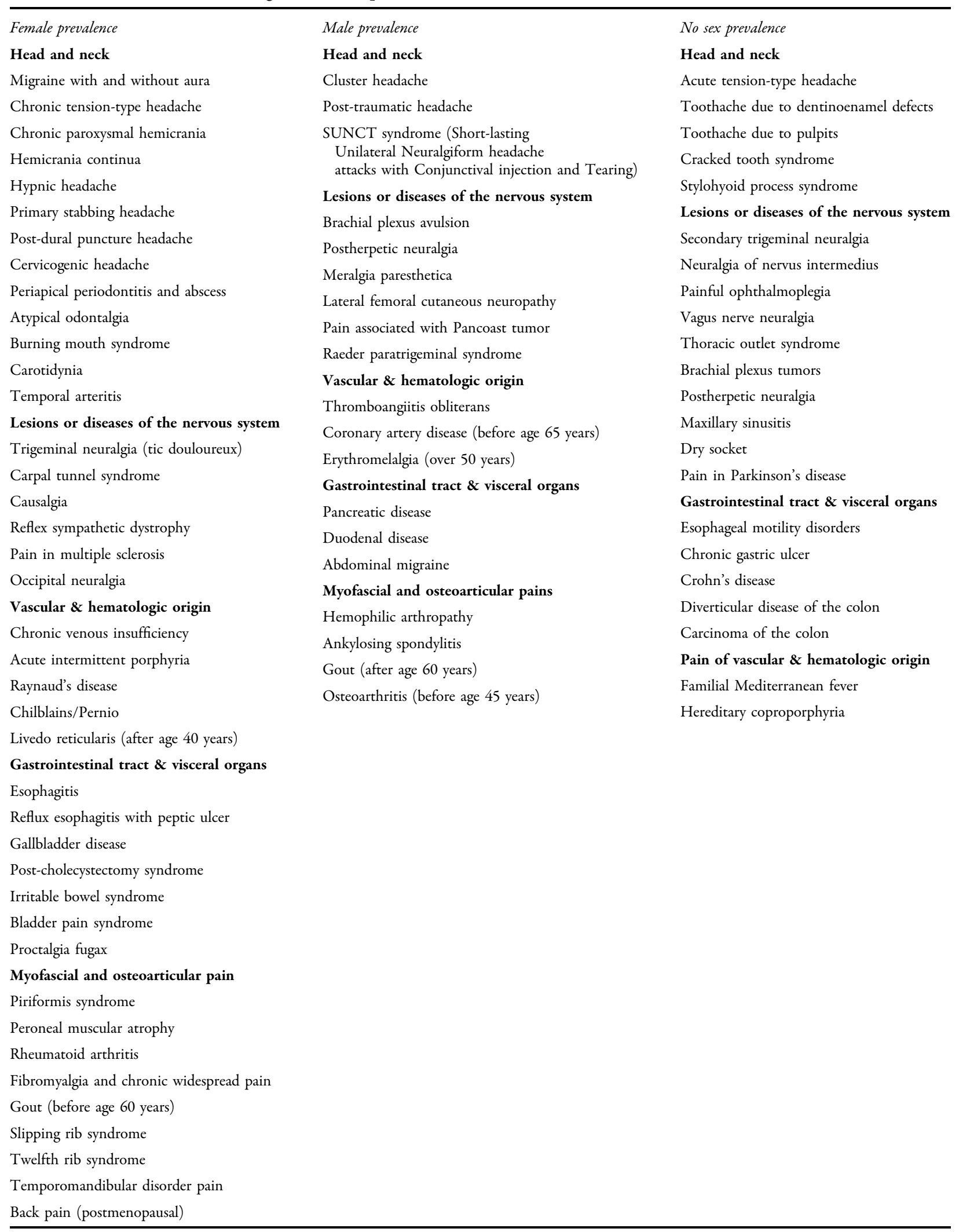


treatment of major chronic diseases, including chronic pain. The International Society for Gender Medicine was established in 2012 [20].

In Italy, the orientation towards gender differences in diagnosis and treatment began to spread in the late 1990s, when the Ministries for Equal Opportunities and Health produced a report called "A health fit for women" that highlighted the consistent lack of attention and inadequate responses to women's health issues across a range of conditions [21]. In 2005, a technical panel was convened under the patronage of the Minister of Health and including the Istituto Superiore di Sanità, the Italian Medicines Agency (AIFA), the Regional Health Services Agency (AgeNaS), universities, and the Italian Society of Pharmacology to formulate guidelines for addressing gender gaps in clinical and pharmacological research. In 2008, the Istituto Superiore di Sanità and the Italian Society of Pharmacology hosted a roundtable meeting called "Gender medicine, an opportunity not to be missed" as part of the Third National Seminar on Women's Health. In the same year, the National Bioethics Committee published a report titled "Pharmacological experimentation on women". Prompted by these initiatives, the AIFA urged pharmaceutical companies to process data disaggregated by gender and to design gender-oriented research, so that treatments could be tailored based on an increased awareness of the different responses to treatment between men and women $[22,23]$. AIFA introduced the concept of "gender equity" into evaluation criteria and established the Working Group on Drugs and Gender to investigate gender-specific problems in the regulatory environment for pharmaceuticals [24].

Indeed, clinical data indicate that men and women exhibit differences in the epidemiology and natural history of certain diseases, including some chronic pain-related pathologies. So far, several hypotheses have been formulated to explain this gender difference, including sex hormones and reproductive and genetic factors. However, none of these hypotheses have gathered enough convincing evidence to impact clinical prescribing patterns, as in most cases the evidence is conflicting. This is particularly the case for pain treatment.

\section{METHODS}

An Expert Group was convened to review the literature on pain conditions that are overrepresented in women. This group was made up of clinicians and medical researchers with expertise in migraine (C.T.), rheumatoid arthritis (F.A.), fibromyalgia (L.B.), and bladder pain syndrome (E.C.), as well as expertise in rehabilitation (G.B.). This report also includes a discussion on pain mechanisms underlying the sex differences (P.S.) and the unmet needs related to the topics covered herein (R.C.). The aim of this group was to examine how pain differs between the genders, not only the macroscopic differences, such as hormonal patterns, but also more promising lines of research on neuroinflammation, the role of the immune system, and non-neuronal cells, microglia, and $\mathrm{T}$ cells. Any pharmacological strategy for chronic pain can usually be enhanced by rehabilitation to limit or delay the development of disability. Therefore, the authors provide a perspective overview on these relevant clinical issues of pain in women, also reporting potential strategies to counteract pain-related disability and improve the quality of life (QoL) and social participation of women with chronic disabling pain.

This article is based on previously conducted studies and does not contain any new studies with human participants or animals performed by any of the authors.

\section{RESULTS}

\section{Gender-Related Pain Mechanisms}

There is indisputable evidence that chronic pain conditions occur with a higher prevalence in females than males and that pain is reported more frequently by women $[2,25,26]$. There may also be differences in pain severity between the sexes, but this is particularly difficult to assess in clinical practice, because multiple variables are involved including potential differences in responsiveness to pain treatments between men and women [25]. 
Sex differences in response to experimental pain have been investigated using various stimulus modalities (e.g. mechanical, electrical, thermal, ischemic, and chemical stimuli) $[1,2,27]$. In recent years, conditioned pain modulation and dynamic pain modulatory processes have been investigated with highly sophisticated experimental pain models [28]. Results are not unequivocal and seem to depend on the type of pain stimulation; nonetheless, research consistently indicates that women show greater sensitivity to pain than men do across multiple stimulus modalities [25, 29].

Unfortunately, the mechanisms underlying these differences are yet to be explained, but they have been studied in animal models. These models allow a better manipulation of hormonal states and have tried to demonstrate the impact of sex hormones on pain responses. Sex hormones and their receptors are expressed in areas associated with nociceptive transmission. For example, testosterone decreases pain sensitivity, and a low testosterone level has been found in many chronic pain conditions. In contrast, the effects of estrogen and progesterone on pain are more complicated, with both pro- and antinociceptive properties [29-34].

Moreover, the role of sex hormones in modulating immune and inflammatory responses is increasingly recognized. Estrogen and testosterone are major regulators of the immune system. Hormones interact with their receptors on immune cells and affect their production, maturation, differentiation, and functioning, modulate the production of cytokines, and condition the development of immune-related diseases [35]. Although a comprehensive review of sex differences in immunity goes beyond the scope of this review, the general hypothesis is that females develop stronger innate and adaptive immune responses than males. Females have stronger responses to antigens, reject allografts more rapidly, have a reduced incidence of certain tumors, and generally resist bacterial and viral infections, and parasitic infestations more successfully than males. The greater immune responsiveness in females is also evident in their increased susceptibility to autoimmune diseases [36].
In recent years, preclinical studies have shown consistent differences between males and females concerning the role of neuroinflammation in pain onset, maintenance, and development [36, 37]. Preclinical studies have demonstrated that chronic pain, in particular neuropathic pain, involves a pathological interaction between neurons, inflammatory immune cells, and glial cells, as well as a wide cascade of pro- and anti-inflammatory cytokines $[38,39]$. Neuronal injury not only results in profound modifications to the activity of sensory neurons and their central projection pathways, but is also coupled with a sustained immune-inflammatory response at sites of chronic pain processing (i.e. nerves, dorsal root ganglion, spinal cord, and brain) [39]. Resident cells are activated and immune cells are recruited at the site of the injured nerve, in the dorsal root ganglion and in the spinal cord [39]. Communication among immune cells and immune-like glial cells at the sites of pain transmission occurs via immune cell-derived inflammatory cytokines and chemokines, which are crucial mediators of the development and maintenance of persistent pain [40]. The development and maintenance of chronic pain is commonly caused by activation of spinal cord glia. Microglia and astrocytes have a well-documented role in pain facilitation, modulating neuronal synaptic function and excitability through various mechanisms [41, 42]. The immune mediators released by these cells diffuse and bind to receptors on presynaptic and postsynaptic terminals in the spinal dorsal horn, where they modulate excitatory and inhibitory synaptic transmission, resulting in nociceptive hypersensitivity. In parallel with immune activation within the nervous system, the peripheral immune system has also been consistently shown to have a pivotal role in the induction and maintenance of neuropathic pain $[36,37]$.

Microglia and infiltrating immune cells, including $\mathrm{T}$ lymphocytes, are the main elements involved in neuroinflammation. According to a number of recent studies, the initiation and maintenance of neuroinflammation differs between sexes. For example, chronic pain behavior of male and female mice is 
mediated by different immune cells in the spinal cord. Several researchers induced allodynia in mice of both sexes and found that inhibitors that block microglia or toll-like receptor 4 activation reversed allodynia only in male animals $[43,44]$. These data indicate that microglia are largely involved in the pathogenesis of chronic pain in males, while $\mathrm{T}$ cells drive neuroinflammation in females [36, 37, 45, 46].

Differences between males and females in the role of non-neuronal cells in pain appear to be qualitative rather than quantitative. It has been suggested that testosterone levels determine the type of cells that become activated during the development of neuropathic pain; in the presence of low testosterone, adaptive immunity, particularly $\mathrm{T}$ lymphocytes, is more involved in pain, which is what happens in female mice [37]. Interestingly, the role of microglia in pain becomes evident in female mice that have been genetically modified to knock out the T-cell response. Therefore, in females, the pain response to nerve injury is normally sustained by $\mathrm{T}$ cells, but when these cells are not present, the inflammatory responses are mediated by microglia [37]. Although these experimental observations have not yet been translated to humans, they suggest that sex differences in pain may be mediated by sex differences in the immune system rather than the nervous system, which may open up a new pathway for research into pain mechanisms and treatments.

Another topic of research is whether the response to pain therapy is gender-related $[47,48]$. Gender differences in drug response can be ascribed to either pharmacokinetic or pharmacodynamic characteristics. Males and females have different body composition and metabolism. Although all aspects of pharmacokinetics may differ slightly between males and females, sex differences in drug metabolism are considered to have the greatest role in pharmacokinetic variability. The expression of cytochrome $\mathrm{P} 450$ enzymes involved in hepatic phase I metabolism varies by sex in both humans and animals, therefore affecting final drug concentrations. Renal drug excretion is also affected by sex, specifically the clearance of drugs that are actively secreted, since the activity of transporters in the kidney is modulated by sex hormone differences. Considering the many hormonal variations that occur in females during their life, it is important to identify pharmacokinetic variations due to hormonal fluctuation, but the few studies that have been conducted have yielded conflicting results (extensively reviewed by Gandhi and colleagues [49]).

Several studies have addressed the question of sex differences in the response to opioid drugs [50]. Animal studies have suggested the presence of sexual dimorphism in mu-opioid receptors (MOR), with males showing greater MOR expression and better opioid binding in the rostrocaudal axis of the periaqueductal gray [50]. The MOR second messenger-signaling cascade also differs between the sexes $[50,51]$. Acute and persistent pain assays in preclinical studies have shown that morphine is a more effective analgesic in males than females [47].

Clinical evidence is less consistent, since some studies have reported no sex differences in the dose of opioids required for pain relief, and others have found that women require either lower or higher doses of opioids [10]. These contradictory results may have been influenced by the type, dose, and route of administration of the drugs (e.g. fixed doses or patient-controlled analgesia) as well as differences in the perception of pain at baseline, age-related hormonal status, and comorbid psychiatric disorders [10]. Irrespective of any differences in the analgesic effect of morphine, it is generally agreed that women are more likely to develop adverse effects, including nausea, dysphoria, headache, and vomiting $[52,53]$.

\section{Migraine}

Migraine is a common neurological disease that shows a higher prevalence in women than in men. The 1-year prevalence of migraine in Europe is $22 \%$, but is $27.7 \%$ in women and $14.8 \%$ in men [54]. Migraine is characterized by recurrent attacks of headache associated with nausea, vomiting, and sensitivity to light and noise, and worsened by routine physical activity. It can occur in a chronic ( $\geq 15$ days/month) 
form, which is resistant to conventional treatment and causes marked disability. One-third of individuals with migraine have $\geq 5$ migraine days/month [55]. According to the Global Burden of Disease Study 2016, migraine is the most disabling neurological disorder and the sixth most disabling condition in the world $[56,57]$.

\section{Diagnosis}

The diagnosis of migraine is made according to the International Classification of Headache Disorders criteria (Table 2) [58]. Research suggests that attacks are more frequent, last longer, and are more severe in women than men [59]. In addition, the associated symptoms, such as nausea, vomiting, and light and noise sensitivity, are generally more prevalent and more severe in women than men [59].

A minority of migraineurs experience aura, a reversible neurological symptom-visual, sensory, speech/language, motor, brainstem, or retinal type-which usually precedes that painful phase and lasts from a few minutes to 60 min. During the aura, patients may experience only one of these neurological symptoms, while others report a range of symptoms that arise sequentially. Headache usually follows the aura within $60 \mathrm{~min}$.

\section{Reasons behind the Higher Prevalence of Migraine in Women}

Several explanations have been proposed for the higher prevalence of migraine in women. There is evidence that women have different pain tolerance or thresholds than men and may seek medical advice more readily than men do, at least for pain in general, but no convincing data exist that suggest this is the case with migraine. Similarly, animal data do not convincingly show sex differences in pain tolerance or threshold, so it is unlikely that the higher female prevalence of migraine can be explained by sensitivity alone [27, 60]. Another theory is that the high migraine prevalence in women is explained by sex differences in responsiveness, tolerance, pharmacokinetics, and/or pharmacodynamics for many analgesics. However, this is unlikely since such differences are most marked with opioids [60], a class of drugs that is poorly effective for relieving migraine pain. A third, and probably more likely, explanation is that hormones are involved in the pathophysiology of migraine. In many orofacial pain conditions, fluctuations in levels of estrogen, progesterone, and androgens are associated with changes in the pain experience $[60,61]$. The premenstrual changes in sex hormones are associated with an increased risk of developing attacks in female migraineurs $[1,51]$. Moreover, pregnancy, when plasma levels of female hormones are high and stable, is generally associated with an improvement of migraine frequency, while menopause is a transitional phase, when migraine can either improve or worsen $[1,51]$.

\section{Treatment}

Migraine treatment can be both symptomatic and preventive. The primary goal of symptomatic treatment is to reduce the pain and restore function/QoL in the shortest possible time. The goal of preventive medications is to reduce the frequency, intensity, and duration of attacks and to prevent their progression from episodic to chronic, which occurs at a rate of approximately $3 \%$ per year [62].

Treatment strategies for migraine should include patient education, lifestyle changes, management of triggers, and acute/preventive pharmacology. Generally, preventive treatment is indicated for patients experiencing $>4$ migraine days/month and having an unsatisfactory response to acute treatment.

The mainstays for the acute treatment of migraine are nonsteroidal anti-inflammatory drugs (NSAIDs) and triptans. These drugs can be used alone or in combination with antiemetics. Ergotamine derivatives are used less frequently because of their potential toxicity. The formulations and routes of administration need to be carefully selected based on the attack characteristics and the patient's preferences. Timing of administration is also important, with intake early during the course of the migraine having the highest chance of rapid and complete pain relief. Very recently, the FDA approved the new gepants for the acute treatment of migraine. These are small molecules that antagonize the calcitonin gene-related peptide (CGRP) receptor 
Table 2 Diagnostic criteria for migraine according to the International Classification of Headache Disorders [58]

Diagnostic criteria
A. At least five attacks fulfilling criteria B-D
B. Headache attacks lasting $4-72 \mathrm{~h}$ (not treated)
C. Headache has at least two out of the four characteristics below:
Unilateral location
Pulsating quality
Moderate or severe pain intensity
Aggravation by or causing avoidance of routine physical activity
D. During headache at least one of the following:
Nausea and/or vomiting
Photophobia and phonophobia
E. Not better accounted for by another diagnosis

(C) International Headache Society 2013-2018

and have been developed specifically for migraine.

Agents available for preventive therapy include beta-blockers, anti-serotonergic drugs, antidepressants, calcium antagonists, and antiepileptic drugs (Table 3). No single treatment is effective for every patient; therefore, therapy needs to be individualized, often incrementally over time. In chronic migraine, onabotulinum toxin type A can be used with a specific 31/39 injection protocol [63].

Recently, three monoclonal antibodies targeting CGRP (erenumab, galcanezumab, and fremanezumab) were approved by the FDA and the European Medicines Agency (EMA) for the prevention of migraine in patients who have $>4$ migraine days/month. These drugs are injected subcutaneously monthly with the exception of fremanezumab, which can also be injected quarterly.

A recent review of randomized controlled trials (RCTs) on the effect of nutritional supplements in migraine patients suggested a role for supplementation with magnesium, riboflavin, niacin, coenzyme Q10, vitamin D, vitamin B12, and alpha-lipoic acid. Being generally well tolerated, these compounds can be tried alone or in combination with routine treatments [64].

\section{Future Perspectives}

Given the marked gender differences reported in migraine, it is vital to investigate gender differences in the efficacy and safety of drugs for acute and preventive treatment. Future research also needs to identify factors that protect against worsening of the disease, particularly for women who are at higher risk of developing chronic migraine. Biomarkers of drug response would be very useful, saving time and money within the health system and ensuring higher efficacy and improved tolerability for patients. Migraine begins in childhood and adolescence, and there is a lack of therapeutic options for patients in this age range. The International Headache Society recently published guidelines for clinical trials in children and adolescents [65]. Hopefully, this will stimulate further 
Table 3 Preventive drugs for migraine with strong evidence of efficacy

\begin{tabular}{l}
\hline Drug class/drug name \\
\hline Beta-blockers \\
Propranolol \\
Metoprolol \\
Atenolol \\
Anti-epileptics \\
Valproic acid \\
Topiramate \\
Antidepressants \\
Amitriptyline \\
Venlafaxine \\
Calcium antagonists \\
Flunarizine \\
CGRP-targeting monoclonal antibodies \\
Erenumab \\
Fremanezumab \\
Galcanezumab \\
Onabotulinum toxin A (for chronic migraine) \\
CGRPcing
\end{tabular}

CGRP calcitonin gene-related peptide

research, also focusing on gender-related and hormonal-related differences.

\section{Rheumatoid Arthritis}

Rheumatoid arthritis (RA) is an autoimmune inflammatory joint disease that may also affect the pulmonary, nervous, and cardiovascular systems [66]. The systemic manifestations of RA (e.g. fatigue, pain, and both constitutional and mental health problems) affect the patients' QoL [67]. The pain experienced by RA patients is due to active disease, as well as mechanical and neuropathic conditions, fibromyalgia, treatment side effects, and psychosocial conditions such as anxiety, depression, sleep disturbances, sexual dysfunction, and disability [67-69].

\section{Etiology}

The causes of RA-related pain may differ during and between inflammatory flares [68]. Synovial inflammation stimulates bradykinin, prostaglandins, and pro-inflammatory cytokines, such as tumor necrosis factor alpha (TNF- $\alpha$ ), interleukin-1 (IL-1), IL-6, and transforming growth factor beta (TGF- $\beta$ ), which significantly contribute to pain generation and maintenance by sensitizing peripheral nerves [68]. Synovitis is associated with activated spinal cord astrocytes and microglia, as well as alterations in spinal cord substance $P, \gamma$-aminobutyric acid (GABA), and CGRP neurotransmitters and their receptors $[68,69]$, thus leading to the production of IL-1, IL- 6 , and TNF- $\alpha$, and facilitating the transmission of pain, which may also be exacerbated by greater ascending activation and less descending inhibition [68, 70, 71]. Moreover, sex differences in innate and adaptive immune systems have been shown in rodent models, with male mice utilizing microglia in the spinal cord to mediate pain and females preferentially using $\mathrm{T}$ cells. These differences have been hypothesized as one of the mechanisms causing the differential chronic pain experience between the sexes [46].

Furthermore, central sensitization affects the nerves in inflamed joints and reduces pain thresholds in surrounding tissues [72, 73]. Pain may also arise as a result of radiographically detectable, structural changes in bone; the destruction of cartilage can cause mechanical pain due to secondary osteoarthritis (OA) even if the patient's RA is in remission or showing low disease activity [68].

\section{Diagnosis}

The 28-joint Disease Activity Score (DAS28) is used to assess joint inflammation in RCTs. However, many concurrent factors may affect the relationship between DAS28 and inflammatory disease activity.

Inflammation and concomitant painful conditions affecting the joints, such as OA, increase visual analogue scale (VAS) scores and tender joint counts (TJCs); the interpretation of 
Table 4 Potential exams and tests for typical symptoms of fibromyalgia

\begin{tabular}{|c|c|c|}
\hline Symptom & Blood tests & $\begin{array}{l}\text { Instrumental tools/clinimetrics for } \\
\text { diagnosis }\end{array}$ \\
\hline \multirow[t]{4}{*}{ Intensity and type of pain } & ESR & NRS \\
\hline & CRP & Semiotics of pain \\
\hline & $\mathrm{CPK}$ & \\
\hline & $\mathrm{LDH}$ & \\
\hline \multirow[t]{3}{*}{ Stiffness } & GAD antibodies & Zone mapping \\
\hline & & Trigger point identification \\
\hline & & Spasmophilia test \\
\hline \multirow[t]{2}{*}{ Hyperreflexia } & Electrolytes & Spasmophilia test \\
\hline & Vitamin D & \\
\hline \multirow[t]{2}{*}{ Small-fiber neuropathy } & Skin biopsy & DN4 Questionnaire \\
\hline & $\begin{array}{l}\text { Confocal optical } \\
\text { microscopy }\end{array}$ & \\
\hline Metabolic alterations & Lactate-ammonia test & $\begin{array}{l}\text { Lactate-ammonia test on } \\
\text { cycloergometer }\end{array}$ \\
\hline \multirow[t]{3}{*}{ Trigger } & Arthrosis & X-ray \\
\hline & Other conditions & MRI scan \\
\hline & & Ultrasound imaging \\
\hline \multirow[t]{8}{*}{ Muscular fatigue } & $\mathrm{CPK}$ & Surface EMG \\
\hline & $\mathrm{LDH}$ & EMG \\
\hline & TSH & \\
\hline & Statin intake & \\
\hline & Vitamin B12 & \\
\hline & Folate & \\
\hline & Selenium & \\
\hline & Magnesium & \\
\hline \multirow{2}{*}{$\begin{array}{l}\text { Gastrointestinal alterations and intolerances (gluten, } \\
\text { wheat, lactose) }\end{array}$} & Fecal calprotectin & Bioimpedance \\
\hline & Specific tests & Nutritional assessment \\
\hline
\end{tabular}

$\overline{C P K}$ creatine phosphokinase, CRP C-reactive protein, DN4 Douleur Neuropathique 4, EMG electromyography, ESR erythrocyte sedimentation rate, $G A D$ glutamic acid decarboxylase, $L D H$ lactate dehydrogenase, $M R I$ Magnetic Resonance Imaging, NRS Numerical Rating Scale, TSH thyroid-stimulating hormone 
the DAS28 is also affected by variations in pain processing which coincide with joint inflammation [74]. One Italian cross-sectional study of 292 RA patients with a mean disease duration of $11.6 \pm 8.5$ years $(80.5 \%$ female, mean age 63 years) found that the patients with concomitant fibromyalgia had higher TJCs and DAS28 scores than those with RA alone even though disease activity (assessed on the basis of erythrocyte sedimentation rate [ESR] and swollen joint count $[\mathrm{SJC}]$ ) were similar between the two groups [75]. In another cross-sectional study on 102 women with early RA, Bilberg and colleagues found that one-third of them also satisfied the criteria for widespread pain, and this subgroup reported fatigue, anxiety and depression, a larger number of tender joints, more intense pain, worse global health, and greater limitations in everyday activities, despite a level of inflammation similar to that in the group without widespread pain [76]. Furthermore, the study by Bilberg and other studies have shown correlations between RA and neuropathic pain, sleep, and emotional health, suggesting the presence of generators of noninflammatory pain [76-79]. RA seems to increase the prevalence of sleep and bipolar disorders, depression, and anxiety, particularly among women [80]. The association between RA and depression seems to be bidirectional: RA increases the risk of depression, and depression can increase sensitivity to the pain associated with RA [69, 81].

Many RA patients experience disabilities or difficulties in carrying out their everyday activities that adversely affect their financial situation. This is particularly true in postmenopausal women, and the fact that the difference does not seem to be due to radiographically detectable joint destruction suggests that it is more related to changes associated with menopause [82]. Worsening Health Assessment Questionnaire (HAQ) scores reflect a poorer QoL and functional deficits, and disability can aggravate depression and sleep disorders, increase social isolation, and worsen the perception of pain in patients with RA $[69,77]$.

\section{Treatment}

In most patients, RA can be controlled with glucocorticosteroids and traditional diseasemodifying antirheumatic drugs (DMARDs) such as methotrexate; biological drugs should only be considered in patients with very advanced or severe disease $[68,83]$. Because of the often slow onset of action of DMARDs, and the fact that inflammation is one of the causes of RA pain, patients often use NSAIDs, although these agents are not indicated for long-term disease control $[68,83]$. Although the use of simple analgesics such as paracetamol is not strongly supported by evidence from RCTs, the 17-country evidence, expertise and exchange (the 3e Initiative) collaborative project recommends using paracetamol and NSAIDs to control persistent pain [84]. Tricyclic antidepressants (TCAs), such as imipramine, dothiepin, and amitriptyline, are inhibitors of serotonin and norepinephrine reuptake and neuronal sodium channels [85], but have nonserotonergic properties that lead to differences in their antinociceptive effects [68]. The results of clinical trials of TCAs involving RA patients are variable; a Cochrane systematic review of eight placebo- or active intervention-controlled trials of antidepressants found that there was insufficient evidence to recommend their use in the treatment of RA-related pain [85]. Despite the variable evidence, the $3 e$ recommendations include TCAs as possible adjunctive drugs in the subpopulation of RA patients with inflammatory arthritis [84]. It is worth noting that although appropriate analgesic treatment can reduce TJCs and improve patient-reported general health, these treatments do not suppress the underlying disease [68].

The acceptance of chronic pain and the development of coping skills and self-efficacy contribute to the QoL of RA patients, and psychological interventions such as cognitive behavioral therapy (CBT) may be effective [86]. In RA patients with moderately active disease and limited joint erosions, aerobic exercises and dynamic strength training may also be advantageous. Exercise does not increase pain or disease activity in RA patients with moderate/low disease activity or in remission; resistance exercise is safe and can significantly and 
clinically improve most RA-related pain and disability outcomes [87]. Finally, patients with severe and unremitting pain in a single joint may benefit from joint replacement surgery.

\section{Fibromyalgia}

Fibromyalgia is a chronic condition characterized by widespread pain. Patients with fibromyalgia also commonly experience sleep disturbances, cognitive disorders, depression, tingling sensation in the limbs, gastrointestinal symptoms, and morning stiffness [88, 89]. These patients may also have chronic fatigue syndrome (CFS), mood disorders, tension-type headaches, migraine, and irritable bowel syndrome [88].

In fibromyalgia patients, pain is not the result of nociception, nor is it caused by an obvious injury or impairment in the somatosensory nervous system. Therefore, the International Association for the Study of Pain (IASP) has defined a new concept for this kind of pain: nociplastic pain, which "arises from altered nociception despite no clear evidence of actual or threatened tissue damage causing the activation of peripheral nociceptors or evidence for disease or lesion of the somatosensory system causing the pain" [90].

The prevalence of fibromyalgia in the general population ranges from 0.2 to $6.6 \%$, being between 2.4 and $6.8 \%$ among women and between 0.6 and $15 \%$ in special populations, such as the elderly, people accessing primary care services, and people of low socioeconomic status; in urban areas, the prevalence is estimated to be between 0.7 and $11.4 \%$ [88, 89]. The prevalence of fibromyalgia is eight- to ninefold higher in women than in men [91]. The negative social and economic impact of fibromyalgia has been well documented [88].

Pain, particularly if prolonged, is often associated with "fibro fog", whose symptoms include memory disorders and difficulty concentrating. Patients presenting with fatigue experience work difficulties; their unintentional fatigue can be long-lasting and a source of frustration.
When assessing a fibromyalgia patient, we observe symptoms associated with neuropathic pain, such as allodynia, hyperalgesia, and smallfiber neuropathy, in approximately 40 to $50 \%$ of cases [92]. These patients often have comorbid pain conditions, including chronic lumbago, painful interstitial cystitis, and temporomandibular disorders [93]. The emotional response to pain in these patients may include alexithymia, anxiety, and a tendency to catastrophize.

\section{Diagnosis}

Patients with fibromyalgia usually have normal blood test results, including inflammatory markers. Because of their symptomatology of widespread pain, sleep disorders, and fatigue, a rheumatological evaluation is required to exclude inflammatory pathologies, such as polymyalgia rheumatica, polymyositis, neurological diseases, myasthenia, Parkinson's disease, diabetes, osteomalacia, and neuroendocrine and connective tissue disorders.

Table 4 provides a list of the most common and useful examinations related to specific symptoms reported in fibromyalgia patients. It is crucial to determine whether pain is the main symptom, whether it is related only to muscles, or whether there is also articular involvement. A comprehensive pain assessment and characterization includes electromyography (EMG) and nerve conduction studies for small-fiber neuropathy [94], the Douleur Neuropathique 4 (DN4) Questionnaire, and the evaluation of pain extent and severity using the VAS. In fibromyalgia, the basal examinations and the standard EMG are generally negative. Additionally, it is important to measure the intensity and diffusion of pain, and evaluate concurrent symptoms, such as stiffness, rigidity, and hyperreflexia. Lactic acid accumulation, as well as any metabolic impairment secondary to bad muscular use, including the evaluation of spasmophilia, should be considered $[95,96]$. The identification of localized OA as a trigger, poor posture and work-related factors should be investigated as well as muscle metabolism through the ischemic lactate-ammonia test and the evaluation of muscle damage by measuring 
enzymes such as lactate dehydrogenase (LDH), creatine phosphokinase (CPK) along with thyroid hormones (TSH), ferritin, vitamin D (25$\mathrm{OH}$ ) [97] and blood count. A more detailed diagnostic evaluation can be performed using surface EMG, which can estimate a reliable value of the red-white fiber ratio. These specialized investigations allow the development of an adapted physical activity program, with the aim of re-educating the musculature. Finally, preliminary studies have suggested assessing the presence in saliva of potential diagnostic biomarkers, which can be helpful to differentiate patients with fibromyalgia from patients with inflammatory pain related to RA or with localized pain caused by headache. This field of research opens up new diagnostic challenges [98].

\section{Differences in Pain between Men and Women}

The male patient with fibromyalgia typically presents fewer tender loci of pain, but these are nevertheless associated with significant anxiety and marked fatigue. In a study conducted on 2,435 German patients with RA, where the authors adopted the 2016 criteria for fibromyalgia, women accounted for $58.7 \%$ of all fibromyalgia cases. Women experienced more symptoms than men did, with a mean of 4.7 symptoms in women versus 3.7 in men, generalized pain present in $36.8 \%$ of women versus $32.4 \%$ of men, and a mean polysymptomatic distress score of 10.2 versus 8.2, respectively [99]. The study also highlighted a linear relation between being female and the presence and severity of fibromyalgia [99].

Why does fibromyalgia affect women more than men? Testosterone deficiency is linked to a high risk of inflammation of the nociceptive nervous system and subsequent chronic pain, which can be treated using a transdermal testosterone gel. Indeed, testosterone therapy has been suggested to reduce pain severity [100]. Nitric oxide (NO) has a suppressive effect on oxidative phosphorylation, leading to an excess of glycolysis by-products during muscular exercise. The higher sensitivity of women with fibromyalgia to this mechanism may suggest how foods triggering the formation of NO synthase, along with NO content, may increase fibromyalgia-related pain [88].

As previously reported, gastrointestinal disorders are a common feature of fibromyalgia; in particular, a higher prevalence of gastrointestinal concerns in women with fibromyalgia has been recognized [101]. While appropriate nutrient intake may be effective in reducing these uncomfortable symptoms in fibromyalgia patients [88], these relevant differences confirm the need for a more gender-tailored therapeutic approach [102].

\section{Treatment}

The European League Against Rheumatism (EULAR) guidelines recommend lifestyle changes and physical therapy [103]. However, when patients undergo these interventions, they experience fatigue, which may affect treatment outcomes. Additionally, patients who experience fatigue from the start of treatment tend to give up on these interventions, which means that the treatment of pain and fatigue becomes preponderant. Fatigue in fibromyalgia is caused more by central mechanisms than by exhaustion of muscle contraction mechanisms (peripheral fatigue), suggesting that a tailored approach to fatigue management is required [104].

A patient with fibromyalgia-related pain is difficult to treat, frequently experiencing adverse events, poor adherence, fatigue, and sleep disorders. Therefore, it is important to address the non-restorative sleep patterns of patients with fibromyalgia. A recent systematic review including 16 quantitative studies evidenced the bidirectional association between pain and sleep in fibromyalgia patients: the study results showed that fibromyalgia patients with increased pain experienced less and poorer sleep in the form of lower sleep quality, efficiency and duration, more disturbed sleep, problematic sleep onset latency and total wake time, as well as symptoms of depression [105]. These issues may be overcome with 
management strategies aimed at increasing sleep quality while decreasing pain [105], such as the use of cyclobenzaprine with amitriptyline.

A full characterization of fibromyalgia-related pain can be useful and easily attainable, in order to develop a therapeutic strategy. This means characterizing the patient as well as his/ her experience before, during, and after the therapy. Teaching disease self-management with tailored programs, improving resilience and reducing catastrophizing, and working with the patients' families to identify the underlying causes of the problem are suitable strategies. Fibromyalgia-related pain does not respond to strong opioids, whereas paracetamol and tramadol, which seem to be very effective, come in a range of formulations (sublingual, oral, and extended-release tablet formulations) and are easy to titrate [106]. The neuropathic component and mood disorders can be treated with duloxetine, pregabalin, or venlafaxine. Medical cannabis (sublingual drops and topical decoctions), particularly when administered in the evening, may improve stiffness, sleep disorders, pain, and refractory headache. However, reports from countries where medical cannabis has been used therapeutically for a long time suggest that this treatment is not sufficiently efficacious, except for chronic pain [107-110].

Recently, nutritional factors have been implicated in the development of fibromyalgia. A deficiency in amino acids and vitamins, coupled with the harmful effects of heavy metals (i.e. mercury, cadmium, and lead) may be the underlying cause of muscle pain [88]. A deficit in specific essential nutrients may disrupt pain inhibitory mechanisms while causing fatigue and various fibromyalgia symptoms. Furthermore, the presence of mercury and other toxic elements may affect the bioavailability of essential nutrients [88]. Fibromyalgia patients should correct any suboptimal intake of essential nutrients with an adequate dietary protocol. The achievement of optimal nutrition levels is likely to reduce pain [88].

\section{Future Perspectives}

Some questions in fibromyalgia remain unanswered: Because it affects the female sex more, has fibromyalgia always been present or are we witnessing a greater frequency? How can we prevent it? Which is the most suitable physical activity? What is the appropriate timing for effective treatment? Must treatment be ongoing? How should an underlying therapy be administered and when? What is the relationship between nutrition and fibromyalgia?

\section{Bladder Pain Syndrome}

The European Association of Urology (EAU) defines chronic pelvic pain (CPP) as a "chronic or persistent pain perceived in the pelvic area of either men or women for at least 6 months" [111]. CPP is "often associated with negative behavioral, cognitive, sexual and emotional consequences as well as with symptoms suggestive of lower urinary tract, sexual, bowel, pelvic floor or gynecological dysfunction" [111]. Furthermore, it can be associated with infections, cancer, or other apparent conditions related to pain.

Chronic pelvic pain syndrome (CPPS) is a subclass of CPP not associated with confirmed infections or other local pathologies potentially responsible for pain [111]. In CPPS, pain may arise and be perceived from one or more pelvic organs and can be linked to some systemic conditions, such as chronic fatigue syndrome (CFS), fibromyalgia, or Sjögren's syndrome [111].

One of the most characteristic CPPS in women is bladder pain syndrome (BPS), a "chronic (lasting $>6$ months) pelvic pain, pressure, or discomfort in the urinary bladder and accompanied by at least one other urinary symptom such as a persistent urge to void or increased frequency of urination" [112].

\section{Epidemiology}

It is difficult to determine the prevalence and incidence of BPS from published studies. The lack of confirmed pathophysiological 
explanations, validated diagnostic markers, or standardized diagnostic criteria, together with the overlap between BPS and other diseases of known etiology, sometimes delays and complicates the diagnosis. Therefore, published epidemiological data are difficult to interpret, and have led to considerable variability in reported prevalence and incidence rates. In the published studies, prevalence ranges from 1.8 per 10,000 inhabitants up to $45-51$ per 10,000 inhabitants [113], with a female predominance (5:1 to $10: 1)$ [114, 115]. No differences in prevalence based on race, ethnicity, or age $[114,116,117]$ have been reported $[116,118]$.

\section{Etiology}

The etiology of BPS is still an enigma. Different theories have been proposed to explain the pathophysiology of the pain, but it is generally agreed that the cause is multifactorial.

BPS patients with ulcerative disease have a significantly increased number of mast cells [119]. Mast cells are immune cells containing inflammatory mediators such as histamine, leukotrienes, serotonins, and cytokines $[120,121]$. The release of mast-cell-derived factors causes edema, fibrosis, and the formation of new vessels in the lamina propria, that could be correlated to the principal symptoms of BPS as pain and frequency $[120,122]$.

The urothelium is a high-resistance barrier between the lumen and the underlying layers (vasculature, connective, nervous, and muscular tissues). The dense layer of glycosaminoglycans (GAG) on the luminal surface of the urothelium and the tight intercellular junctions block the passage of ions, solutes, water, and pathogens [123]. Parsons and colleagues showed that a defect in the GAG layer in the urothelial barrier results in symptoms of urgency, frequency, and pain during bladder filling and voiding [120, 124].

In BPS, urothelial cell proliferation is inhibited by the downregulation of genes stimulating cell proliferation and by the upregulation of genes inhibiting cell growth (e.g. antiproliferative factor) [125]. This proliferative block affects the repair of injured or denuded urothelium and impairs the physiological barrier function of the urothelium [123, 126, 127].

BPS presents many typical features of an autoimmune pathology, including chronicity, exacerbations and remissions, clinical response to immunosuppressive agents, and an increased rate of antinuclear antibodies, and sometimes BPS is associated with other autoimmune diseases. Thus, the symptoms of BPS may be epiphenomena occurring as a result of bladder cell injury caused by the primary autoimmune condition [127, 128].

Urinary tract infection with nanobacteria [129] or fungi (Candida and Saccharomyces spp.) [130] may be involved, but patients with BPS generally do not experience urinary infections. It may be that an altered microbiota composition could explain the damage to the urothelium and the resulting mast cell activation, but the involvement of infection in the BPS etiology remains an unresolved issue.

A decrease in the density of the bladder microvasculature has been demonstrated in patients with BPS [131], accompanied by increased expression of hypoxia-inducible factor-1 alpha in the bladder tissue [132]. However, the mechanism underlying the hypoxic condition in the bladder cells of patients with BPS is still unknown.

Central sensitization is an abnormal state of responsiveness to noxious and innocuous stimuli, leading to tenderness beyond the site of injury [133, 134]. It is probably involved in neuropathic and inflammatory pain in patients with BPS. The sensitization of the nociceptive system occurs after repeated or intense noxious stimuli, so that as the threshold decreases, responses (duration and magnitude of dorsal horn neurons) to subsequent inputs and their receptive fields are amplified [133-135]. Furthermore, afferents that are not normally active (the so-called silent afferents) may also become activated by the change $[136,137]$.

\section{Diagnosis}

BPS is a diagnosis of exclusion, in which history, physical examination, and laboratory tests are used to rule out specific diseases that may cause 
pelvic pain [111]. When BPS is suspected, clinical and instrumental diagnostic procedures are primarily aimed at excluding any confounding conditions and phenotyping the disease according to the classification system known as UPOINT [111].

The patient's pathological and pharmacological history is important, particularly the history of pain, which is the "key symptom". Pain is usually described as pressure or discomfort associated with one or more other symptoms, such as increased daytime and/or nighttime urinary frequency. The exclusion of other similar conditions is mandatory $[111,138]$. Pain can be present as suprapubic pressure (sometimes radiating to the groin, vagina, rectum, or sacrum) or discomfort perceived in the bladder, which increases with increasing bladder content, is relieved by voiding, but soon returns [111]. Pain can be exacerbated by food or drink [111, 139]. Sometimes CPPS can be associated with chronic non-urological-associated somatic syndromes (NUAS). According to data from the Multidisciplinary Approach to the Study of Chronic Pelvic Pain (MAPP) network, patients with NUAS report more severe pain-mostly felt outside the pelvis-more severe urinary symptoms, and more recurrent anxiety and depression than patients without this condition [140].

A detailed physical examination of the abdomen, pelvis, and vagina should be carried out, paying specific attention to areas of tenderness. A musculoskeletal and focused neurological examination for tenderness and trigger points should also be undertaken [111], because three-quarters of men and women with CPPS report pain in areas outside the pelvis [141]. Widespread pain is associated with more severe pain symptoms in non-pelvic regions, worse psychosocial health, and poorer QoL, but it does not aggravate pelvic pain or urinary symptoms [141].

The three-day chart is a widely adopted diagnostic instrument used to identify BPS [142], together with the validated symptom and QoL scoring known as O'Leary-Sant Interstitial Cystitis Symptom and Problem Index (ICSI/
ICPI) $[111,143]$. The European Society for the Study of Interstitial Cystitis (ESSIC) guidelines recommend performing abdominal ultrasound and uroflowmetry in order to exclude any confounding disease [138]. Urine dipstick and urine culture should be performed to exclude urinary tract infection, and urine cytology should be tested in patients who are at high risk of urothelial malignancy [111].

Cystoscopy should be performed early in the evaluation of bladder pain [138]. According to several international guidelines, cystoscopy with hydrodistention should be performed to exclude confounding pathologies in patients with BPS [138, 144]. The ESSIC guidelines recommend bladder biopsy during cystoscopy with three samples taken (one from each lateral wall and one from the dome), and provide a classification criteria based on cystoscopy and biopsy findings [111, 138, 144].

There are no clear recommendations about the appropriate hydrodistention procedure (filling volume, duration, and pressure). The National Institute of Diabetes and Digestive and Kidney Diseases (NIDDK) recommends performing a cystoscopy with hydrodistention and anesthesia at a pressure of $80-100 \mathrm{CmH}_{2} \mathrm{O}$ for 1-2 min and repeating twice [145]. Other authors have proposed performing cystoscopy with hydrodistention under anesthesia at a pressure of $100 \mathrm{cmH}_{2} \mathrm{O}$, infusing a volume of $1000 \mathrm{~mL}$ for $1 \mathrm{~min}$, but not more than five times $[144,146]$. Nordling and colleagues suggest cystoscopy with hydrodistention and anesthesia at a pressure of $80 \mathrm{cmH}_{2} \mathrm{O}$, without specifying the volume, for 3 min [144, 147].

According to the American Urological Association guidelines, cystoscopy has no primary role in the diagnosis of uncomplicated BPS [148]. The only cystoscopic finding characteristic of BPS is the presence of Hunner's ulcers [145], usually only present in complicated BPS. The presence of Hunner's lesions or glomerulations in at least three bladder quadrants, with 10 glomerulations per quadrant, is considered positive for BPS, according to NIDDK guidelines [145]. 


\section{Treatment}

The aim of BPS management is to improve the patient's QoL and to possibly meet their expectations [138]. First-line approaches are behavioral modification strategies (voiding, fluid modification, and bladder training) and physiotherapy, especially for patients with pelvic floor dysfunction [111, 138]. Oral medications with amitriptyline and pentosan polysulfate are second-line therapies [138]. Intravesical instillations of anti-inflammatory and analgesic medications or agents that may restore the impaired GAG layer (hyaluronic acid, chondroitin sulfate, alone or in combination, and pentosan polysulfate) are strongly recommended by various international guidelines [111, 138, 148]. Bladder hydrodistention and transurethral resection (or coagulation or laser) of Hunner's lesions (3C type) are recommended as third-line therapeutic approaches [145], whereas fourth-line treatment options include intravesical and trigonal injection of botulinum toxin A (100 units) with or without hydrodistention or sacral neuromodulation [111, 138, 148]. All international guidelines indicate radical surgery with substitution cystoplasty (with supra- or sub-trigonal cystectomy) or urinary diversion (with or without cystectomy) as the final therapeutic options [111, 138, 148].

\section{Pain Rehabilitation in Women}

Rehabilitation clinicians are often involved in the treatment of pain, and chronic pain in particular. Among the people with different chronic pain conditions (such as hip [149] or knee [150] OA, chronic low back pain [151], and fibromyalgia [152]) in rehabilitation units, more are women than men. Chronic pain localized in the spine, including chronic neck and low back pain, is more common in women than men $[17,153]$

Systematic reviews and meta-analyses show that different rehabilitative interventions, such as exercise and some physical modalities, can be effective treatments for chronic pain. There is now growing evidence that exercise is an effective treatment for chronic low back pain. For example, there is up to moderate-quality evidence that exercises focused on the activation of trunk muscles can have clinically important effects for chronic low back pain [154]. Aquatic exercise also reduces low back pain and improves physical function [155]. Moreover, exercise is also effective for low back pain prevention [156]. Regarding knee OA, another pain condition more common in women than men, resistance training is beneficial in terms of reducing pain and improving physical function [157].

Women with fibromyalgia can benefit from rehabilitation, with growing evidence that exercise can reduce the burden of disease and improve physical function and fatigue in people with this condition [158]. Even patients whose disease has been established over several years can improve their ability to undertake activities of daily living after completing evaluation and treatment by a multidisciplinary team composed of physicians, psychologists, nurses, and occupational and physical therapists [159]. However, there is currently evidence for some physical modalities in fibromyalgia, such as transcutaneous electrical nerve stimulation (TENS) [160] or whole-body vibration exercise [161].

In RA of the hand, hand exercises are commonly used to improve pain and hand strength, dexterity, and joint mobility. There are metaanalytical data to show that exercise has some effect on hand function, but its effects on pain remain controversial [162]. In contrast, in OA of the hand, which is another common pain condition in women, exercise can produce moderate beneficial effects on pain, function, and joint stiffness [163].

Some pain conditions, such as dysmenorrhea and pregnancy-related pain, are exclusive to women. There is emerging evidence that exercise can provide a clinically significant reduction in the intensity of menstrual pain [164] and reduce the frequency of low back pain and sick leave due to lumbopelvic pain in pregnant women [165]. Interestingly, acupuncture, which is also used by rehabilitation physicians, has been shown to reduce joint pain to some extent in postmenopausal women with early- 
stage breast cancer and aromatase inhibitor-related arthralgias [166].

The extent to which the different therapies are more effective and more appropriate for women than for men remains to be fully understood. Even if still sparse, there are some findings indicating that the response to rehabilitative therapies can be different in women suffering from chronic low back pain compared with men. For example, pain rehabilitation programs for patients with chronic low back pain, which often include cognitive behavioral therapy along with exercise, seem more effective in women $[167,168]$.

It is important to stress that resilience (i.e. the ability to adapt in the face of life stressors, such as a painful condition) and positive coping behaviors (i.e. the fruitful actions taken to deal with stressful situations) are key components for successful rehabilitation $[169,170]$. In many cases, the rehabilitation actually expands the patient's coping repertoire by offering new strategies to deal with the problems caused by the disease [171]. Indeed, gender variation in disability due to pain, as well as differences in coping strategies, has been recognized in many painful conditions [17], including those mainly affecting women [172]. Different coping strategies have been observed in men and women facing, for instance, low-back pain, with women more likely than men to experience more severe, more frequent, and longer pain, but also responding more aggressively to pain with health-related activities [17]. It may be that the different response to rehabilitation in men and women with low back pain is because females may be more receptive to the new coping strategies offered by rehabilitation. A recent study among patients undergoing minimally invasive transforaminal lumbar fusion established that both genders should experience similar functional outcomes after spinal surgery, suggesting that sex differences in outcomes may be attributable to the access to, or quality of, rehabilitation received by male versus female patients [173], putting emphasis on the still existing differences in the level of rehabilitation care received by females.

Chronic pain can occur as a symptom of a separate neurological condition. For example, pain is common after stroke (e.g. shoulder pain [174]), in peripheral neuropathies, such as those associated with diabetes [175], in movement disorders such as Parkinson's disease [176] and cervical dystonia [177], and in dementia [178], which occurs more frequently in women than men. Given what we know of the differences in the way males and females perceive pain, it is possible that similar gender-related differences exist for pain associated with a neurological disease, but to our knowledge this hypothesis is largely unexplored. This uncertainty is reflected in the rehabilitation strategies that are currently used.

\section{CONCLUSIONS}

All the pathologies described in this review have a markedly higher prevalence in women than men. It is therefore important to investigate the pathophysiological basis for gender differences in the generation of acute pain and maintenance of chronic pain, including the factors that put women at higher risk for developing chronic pain. This is an essential step in understanding gender differences in the efficacy and safety of drugs for acute and chronic pain syndromes and, as in the case of migraine, for preventive treatment. Biomarkers of chronic pain risk and of drug response could be very useful, saving time and money and ensuring higher efficacy and improved tolerability of drugs in patients.

While testosterone deficiency has been linked to a high risk of inflammation in the nociceptive nervous system, more in-depth research is needed to better understand why not all testosterone deficiencies trigger maladaptive responses in the nociceptive system. Diet and nutrition as epigenetic factors influencing the perception of pain are another field of interest suggested by the Expert Group, highlighted by the frequent presence of comorbid gastrointestinal disorders in some pain conditions, such as fibromyalgia. The vicious circle of chronic pain in association with anxiety and depression places a strong emphasis on common neurotransmitters-and therefore shared mechanisms-between these pathologies in women. 
The overall findings from epidemiologic and clinical studies demonstrate that women are at higher risk for many common pain conditions than men. However, decades of laboratory research have not been successful in producing a clear and consistent pattern of sex differences in human pain sensitivity [2]. Data on pain intensity are less consistent and influenced by several methodologic factors, including mode of patient selection in clinical studies and sex differences in the effects of pain treatments [16].

"Big data" and data-mining techniques provide an opportunity to reprocess the substantial amount of clinical data that is already present in the literature but, unfortunately, not yet disaggregated by gender. This could help to elucidate gender differences in the utilization of very well-known and useful drugs, such as paracetamol, or weak opioids, such as codeine. Insights from these analyses will hopefully stimulate further clinical and basic science research, in a bottom-up system focusing on gender-related differences in pain phenotypes, as well as the potential influence of epigenetics on pathways involved in neuroinflammation, immunoreactivity, and the development of maladaptive plasticity. Maladaptive plasticity often results in pain conditions that are more frequently associated with the female than the male gender, such as those described in this article (migraine, dysmenorrhea, chronic fatigue, interstitial cystitis/irritable urethra syndrome, irritable bowel syndrome, and other regional pain syndromes). It is essential that different specialties collaborate to develop gender-related diagnostic and therapeutic guidelines.

Furthermore, continuous education of healthcare professionals and patients can lead to more appropriate management through the optimal use of existing diagnostic tools and therapeutic options.

As a final note, the members of this Expert Group are in agreement in stating that, at the moment, there are no pharmacological options for the management of chronic pain that have been specifically developed for women. Furthermore, aside from migraine-where monoclonal antibodies have been successfully developed as migraine-specific acute and preventive drugs-the treatment of chronic pain is largely managed using drugs that were initially developed for other diseases, such as depression and epilepsy, and that have limited effectiveness and problematic tolerability. For this reason, the World Health Organization ladder for cancer pain relief-which lists paracetamol, NSAIDs, and weak opioids as first and second options-is still used by a large number of doctors to guide treatment decisions for noncancer chronic pain $[179,180]$. New drugs are in the pipeline and will hopefully broaden the armamentarium of options in the future, but they are not yet available for use in the daily battlefield of our outpatient departments. Although a new approach to targeting treatment specifically by gender may be possible based on studies on the interaction between the immune system, inflammation, and pain, we are still very far from a pain treatment which is specifically targeted to gender-related pain conditions.

\section{ACKNOWLEDGEMENTS}

Funding. Medical writing assistance and the journal's open access fee were funded by Angelini, Italy.

Authorship. All named authors meet the International Committee of Medical Journal Editors (ICMJE) criteria for authorship for this article, take responsibility for the integrity of the work as a whole, and has given their approval for this version to be published.

Medical Writing, Editorial, and Other Assistance. Medical writing and editing was provided by Brunilde Iovene on behalf of Springer Healthcare Communications and Catherine Rees of Springer Healthcare Communication, under the direction of the authors. This assistance was supported by Angelini, Italy.

Disclosures. In the last 3 years, Elisabetta Costantini has received honoraria for presentations during meetings or congresses from Astellas and Neomedic International. In the last 
3 years, Paola Sacerdote has received honoraria from Grünenthal, Helsinn Healthcare, and Angelini. In the last 3 years, Cristina Tassorelli has received honoraria for participation in advisory boards for Allergan, ElectroCore, Eli Lilly, Novartis, and Teva; she is on the speakers bureau for Allergan, Eli Lilly, Novartis, and TEVA; she is principal investigator or collaborator in clinical trials sponsored by Alder, Amgen, Eli Lilly, and Teva. She has received grants from the European Commission, the Italian Ministry of Health, and the Italian Ministry of University. Roberto Casale, Fabiola Fabiola Atzeni, Laura Bazzichi, and Giovanna Beretta have nothing to disclose.

Compliance with Ethics Guidelines. This article is based on previously conducted studies and does not contain any new studies with human participants or animals performed by any of the authors.

Data Availability. Data sharing is not applicable to this article, as no data sets were generated or analyzed during the current study.

Open Access. This article is licensed under a Creative Commons Attribution-NonCommercial 4.0 International License, which permits any non-commercial use, sharing, adaptation, distribution and reproduction in any medium or format, as long as you give appropriate credit to the original author(s) and the source, provide a link to the Creative Commons licence, and indicate if changes were made. The images or other third party material in this article are included in the article's Creative Commons licence, unless indicated otherwise in a credit line to the material. If material is not included in the article's Creative Commons licence and your intended use is not permitted by statutory regulation or exceeds the permitted use, you will need to obtain permission directly from the copyright holder. To view a copy of this licence, visit http:// creativecommons.org/licenses/by-nc/4.0/.

\section{REFERENCES}

1. Fillingim RB, King CD, Ribeiro-Dasilva MC, RahimWilliams B, Riley JL 3rd. Sex, gender, and pain: a review of recent clinical and experimental findings. J Pain. 2009;10(5):447-85.

2. Racine M, Tousignant-Laflamme Y, Kloda LA, Dion D, Dupuis G, Choiniere M. A systematic literature review of 10 years of research on sex/gender and experimental pain perception-part 1: are there really differences between women and men? Pain. 2012;153(3):602-18.

3. Racine M, Tousignant-Laflamme Y, Kloda LA, Dion D, Dupuis G, Choiniere M. A systematic literature review of 10 years of research on sex/gender and pain perception-part 2: do biopsychosocial factors alter pain sensitivity differently in women and men? Pain. 2012;153(3):619-35.

4. Riley JL 3rd, Robinson ME, Wise EA, Myers CD, Fillingim RB. Sex differences in the perception of noxious experimental stimuli: a meta-analysis. Pain. 1998;74(2-3):181-7.

5. Amodei N, Nelson-Gray RO. Reactions of dysmenorrheic and nondysmenorrheic women to experimentally induced pain throughout the menstrual cycle. J Behav Med. 1989;12(4):373-85.

6. Averbeck B, Seitz L, Kolb FP, Kutz DF. Sex differences in thermal detection and thermal pain threshold and the thermal grill illusion: a psychophysical study in young volunteers. Biol Sex Differ. 2017;8(1):29.

7. Lautenbacher S, Rollman GB. Sex differences in responsiveness to painful and non-painful stimuli are dependent upon the stimulation method. Pain. 1993;53(3):255-64.

8. Chapman CD, Benedict C, Schioth HB. Experimenter gender and replicability in science. Sci Adv. 2018;4(1):e1701427.

9. Merskey H, Bogduk N, (eds) Classification of chronic pain: descriptions of chronic pain syndromes and definitions of pain terms. Second Edition ed. Seattle, WA, USA: IASP Press; 1994.

10. Pisanu C, Franconi F, Gessa GL, Mameli S, Pisanu GM, Campesi I, et al. Sex differences in the response to opioids for pain relief: a systematic review and meta-analysis. Pharmacol Res. 2019;148104447.

11. Nasser SA, Afify EA. Sex differences in pain and opioid mediated antinociception: Modulatory role of gonadal hormones. Life Sci. 2019;237116926. 
12. Bajaj P, Bajaj P, Madsen H, Arendt-Nielsen L. A comparison of modality-specific somatosensory changes during menstruation in dysmenorrheic and nondysmenorrheic women. Clin J Pain. 2002;18(3):180-90.

13. Aloisi AM, Bachiocco V, Costantino A, Stefani R, Ceccarelli I, Bertaccini A, et al. Cross-sex hormone administration changes pain in transsexual women and men. Pain. 2007;132 Suppl 1S60-7.

14. Samulowitz A, Gremyr I, Eriksson E, Hensing G. "Brave men" and "emotional women": a theoryguided literature review on gender bias in health care and gendered norms towards patients with chronic pain. Pain Res Manag. 2018;20186358624.

15. Berkley KJ. Sex differences in pain. Behav Brain Sci. 1997;20(3):371-80; discussion 435-513.

16. Pieretti S, Di Giannuario A, Di Giovannandrea R, Marzoli F, Piccaro G, Minosi P, et al. Gender differences in pain and its relief. Ann Ist Super Sanita. 2016;52(2):184-9.

17. Unruh AM. Gender variations in clinical pain experience. Pain. 1996;65(2-3):123-67.

18. Lippman A, Rochon Ford A, O'Grady K. Barbara Seaman (1935-2008): pioneer in the women's health movement. CMAJ. 2008;178(8):988.

19. Mazure CM, Jones DP. Twenty years and still counting: including women as participants and studying sex and gender in biomedical research. BMC Womens Health. 2015;1594.

20. Legato M, Glezerman M, editors. The international society for gender medicine: history and highlights. 1st ed. Cambridge: Elsevier Academic Press; 2017.

21. Del gruppo di lavoro "Medicina Donne Salute". Una salute a misura di donna. Rome, Italy: Dipartimento Pari Opportunità; 2001.

22. Baggio $G$, Malorni $W$. The Italian law on gender medicine: a reality and a hope. Ital J Gender-Specific Med. 2019;5(3):105-7.

23. Ministero della Salute. Piano per l'applicazione e la diffusione della Medicina di Genere (in attuazione dell'articolo 3, comma 1, Legge 3/2018). Rome: Italy; 2019.

24. Pani L. Il genere nello sviluppo del farmaco. Rome, Italy; 2013

25. Bartley EJ, Fillingim RB. Sex differences in pain: a brief review of clinical and experimental findings. Br J Anaesth. 2013;111(1):52-8.
26. Boerner KE, Chambers CT, Gahagan J, Keogh E, Fillingim RB, Mogil JS. Conceptual complexity of gender and its relevance to pain. Pain. 2018;159(11):2137-41.

27. Mogil JS. Sex differences in pain and pain inhibition: multiple explanations of a controversial phenomenon. Nat Rev Neurosci. 2012;13(12):859-66.

28. Popescu A, LeResche L, Truelove EL, Drangsholt MT. Gender differences in pain modulation by diffuse noxious inhibitory controls: a systematic review. Pain. 2010;150(2):309-18.

29. Melchior M, Poisbeau P, Gaumond I, Marchand S. Insights into the mechanisms and the emergence of sex-differences in pain. Neuroscience. 2016;33863-80.

30. Aloisi AM. Why we still need to speak about sex differences and sex hormones in pain. Pain Ther. 2017;6(2):111-4.

31. Aloisi AM, Sorda G. Relationship of female sex hormones with pain perception: focus on estrogens. Pain Manag. 2011;1(3):229-38.

32. Craft RM. Modulation of pain by estrogens. Pain. 2007;132 Suppl 1S3-12.

33. Kuba T, Quinones-Jenab V. The role of female gonadal hormones in behavioral sex differences in persistent and chronic pain: clinical versus preclinical studies. Brain Res Bull. 2005;66(3):179-88.

34. Martin VT. Ovarian hormones and pain response: a review of clinical and basic science studies. Gend Med. 2009;6(Suppl):2168-92.

35. Bhatia A, Sekhon HK, Kaur G. Sex hormones and immune dimorphism. Sci World J. $2014 ; 2014159150$.

36. Rosen S, Ham B, Mogil JS. Sex differences in neuroimmunity and pain. J Neurosci Res. 2017;95(1-2): 500-8.

37. Sorge RE, Mapplebeck JC, Rosen S, Beggs S, Taves S, Alexander JK, et al. Different immune cells mediate mechanical pain hypersensitivity in male and female mice. Nat Neurosci. 2015;18(8):1081-3.

38. Austin PJ, Moalem-Taylor G. The neuro-immune balance in neuropathic pain: involvement of inflammatory immune cells, immune-like glial cells and cytokines. J Neuroimmunol. 2010;229(1-2): $26-50$.

39. Calvo M, Dawes JM, Bennett DL. The role of the immune system in the generation of neuropathic pain. Lancet Neurol. 2012;11(7):629-42. 
40. Sacerdote P, Franchi S, Moretti S, Castelli M, Procacci P, Magnaghi V, et al. Cytokine modulation is necessary for efficacious treatment of experimental neuropathic pain. J Neuroimmune Pharmacol. 2013;8(1):202-11.

41. Halassa MM, Fellin T, Haydon PG. The tripartite synapse: roles for gliotransmission in health and disease. Trends Mol Med. 2007;13(2):54-63.

42. Pocock JM, Kettenmann H. Neurotransmitter receptors on microglia. Trends Neurosci. 2007;30(10):527-35.

43. Machelska $H$, Celik MO. Recent advances in understanding neuropathic pain: glia, sex differences, and epigenetics. F1000Res. 2016;52743.

44. Mapplebeck JCS, Dalgarno R, Tu Y, Moriarty O, Beggs S, Kwok CHT, et al. Microglial P2X4R-evoked pain hypersensitivity is sexually dimorphic in rats. Pain. 2018;159(9):1752-63.

45. DiSabato DJ, Quan N, Godbout JP. Neuroinflammation: the devil is in the details. J Neurochem. 2016;139(Suppl):2136-53.

46. Sorge RE, Totsch SK. Sex differences in pain. J Neurosci Res. 2017;95(6):1271-81.

47. Doyle HH, Murphy AZ. Sex differences in innate immunity and its impact on opioid pharmacology. J Neurosci Res. 2017;95(1-2):487-99.

48. Doyle HH, Murphy AZ. Sex-dependent influences of morphine and its metabolites on pain sensitivity in the rat. Physiol Behav. 2018;18732-41.

49. Gandhi M, Aweeka F, Greenblatt RM, Blaschke TF. Sex differences in pharmacokinetics and pharmacodynamics. Annu Rev Pharmacol Toxicol. 2004;44499-523.

50. Packiasabapathy S, Sadhasivam S. Gender, genetics, and analgesia: understanding the differences in response to pain relief. J Pain Res. 2018;112729-39.

51. Loyd DR, Murphy AZ. The neuroanatomy of sexual dimorphism in opioid analgesia. Exp Neurol. 2014;25957-63.

52. Comer SD, Cooper ZD, Kowalczyk WJ, Sullivan MA, Evans SM, Bisaga AM, et al. Evaluation of potential sex differences in the subjective and analgesic effects of morphine in normal, healthy volunteers. Psychopharmacology. 2010;208(1):45-55.

53. Fillingim RB, Ness TJ, Glover TL, Campbell CM, Hastie BA, Price DD, et al. Morphine responses and experimental pain: sex differences in side effects and cardiovascular responses but not analgesia. J Pain. 2005;6(2):116-24.
54. Steiner TJ, Stovner LJ, Katsarava Z, Lainez JM, Lampl $\mathrm{C}$, Lanteri-Minet $\mathrm{M}$, et al. The impact of headache in Europe: principal results of the Eurolight project. J Headache Pain. 2014;1531.

55. Katsarava Z, Mania M, Lampl C, Herberhold J, Steiner TJ. Poor medical care for people with migraine in Europe - evidence from the Eurolight study. J Headache Pain. 2018;19(1):10.

56. GBD 2016 Disease and Injury Incidence and Prevalence Collaborators. Global, regional, and national incidence, prevalence, and years lived with disability for 328 diseases and injuries for 195 countries, 1990-2016: a systematic analysis for the Global Burden of Disease Study 2016. Lancet. 2017;390(10100):1211-59.

57. Global Burden of Disease Study 2013 Collaborators. Global, regional, and national incidence, prevalence, and years lived with disability for 301 acute and chronic diseases and injuries in 188 countries, 1990-2013: a systematic analysis for the Global Burden of Disease Study 2013. Lancet. 2015;386(9995):743-800.

58. Headache Classification Committee of the International Headache Society (IHS) The International Classification of Headache Disorders, 3rd edition. Cephalalgia. 2018;38(1):1-211.

59. Vetvik KG, MacGregor EA. Sex differences in the epidemiology, clinical features, and pathophysiology of migraine. Lancet Neurol. 2017;16(1):76-87.

60. Dussor G, Boyd JT, Akopian AN. Pituitary hormones and orofacial pain. Front Integr Neurosci. $2018 ; 1242$.

61. Shinal RM, Fillingim RB. Overview of orofacial pain: epidemiology and gender differences in orofacial pain. Dent Clin North Am. 2007;51(1):1-18.

62. Bigal ME, Lipton RB. What predicts the change from episodic to chronic migraine? Curr Opin Neurol. 2009;22(3):269-76.

63. Bendtsen L, Sacco S, Ashina M, Mitsikostas D, Ahmed F, Pozo-Rosich P, et al. Guideline on the use of onabotulinumtoxinA in chronic migraine: a consensus statement from the European Headache Federation. J Headache Pain. 2018;19(1):91.

64. Nattagh-Eshtivani E, Sani MA, Dahri M, Ghalichi F, Ghavami A, Arjang P, et al. The role of nutrients in the pathogenesis and treatment of migraine headaches: review. Biomed Pharmacother. 2018;102317-25.

65. Abu-Arafeh I, Hershey AD, Diener HC, Tassorelli C, Clinical Trials Standing C, the C, et al. Guidelines of the International Headache Society for controlled 
trials of preventive treatment of migraine in children and adolescents, 1st edition. Cephalalgia. 2019;39(7):803-16.

66. Smolen JS, Aletaha D, McInnes IB. Rheumatoid arthritis. Lancet. 2016;388(10055):2023-38.

67. Sokka T, Toloza S, Cutolo M, Kautiainen H, Makinen $\mathrm{H}$, Gogus F, et al. Women, men, and rheumatoid arthritis: analyses of disease activity, disease characteristics, and treatments in the QUEST-RA study. Arthritis Res Ther. 2009;11(1):R7.

68. Atzeni F, Masala IF, Salaffi F, Di Franco M, Casale R, Sarzi-Puttini P. Pain in systemic inflammatory rheumatic diseases. Best Pract Res Clin Rheumatol. 2015;29(1):42-52.

69. Chancay MG, Guendsechadze SN, Blanco I. Types of pain and their psychosocial impact in women with rheumatoid arthritis. Womens Midlife Health. $2019 ; 53$.

70. Atzeni F, Nucera V, Masala IF, Sarzi-Puttini P, Bonitta G. Il-6 Involvement in pain, fatigue and mood disorders in rheumatoid arthritis and the effects of Il-6 inhibitor sarilumab. Pharmacol Res. $2019 ; 149104402$.

71. Schaible HG, von Banchet GS, Boettger MK, Brauer R, Gajda M, Richter F, et al. The role of proinflammatory cytokines in the generation and maintenance of joint pain. Ann N Y Acad Sci. 2010;119360-9.

72. Kaplan CM, Schrepf A, Ichesco E, Larkin T, Harte SE, Harris RE, et al. Association of inflammation with pronociceptive brain connections in rheumatoid arthritis patients with concomitant fibromyalgia. Arthritis Rheumatol. 2020;72(1):41-6.

73. Sarzi-Puttini P, Atzeni F, Mease PJ. Chronic widespread pain: from peripheral to central evolution. Best Pract Res Clin Rheumatol. 2011;25(2):133-9.

74. Leeb BF, Andel I, Sautner J, Nothnagl T, Rintelen B. The DAS28 in rheumatoid arthritis and fibromyalgia patients. Rheumatol (Oxf). 2004;43(12):1504-7.

75. Salaffi F, Di Carlo M, Carotti M, Sarzi-Puttini P. The subjective components of the Disease Activity Score 28-joints (DAS28) in rheumatoid arthritis patients and coexisting fibromyalgia. Rheumatol Int. 2018;38(10):1911-8.

76. Bilberg A, Bremell T, Bjersing J, Mannerkorpi K. High prevalence of widespread pain in women with early rheumatoid arthritis. Scand J Rheumatol. 2018;47(6):447-54.

77. Grabovac I, Haider S, Berner C, Lamprecht T, Fenzl $\mathrm{KH}$, Erlacher L, et al. Sleep quality in patients with rheumatoid arthritis and associations with pain, disability, disease duration, and activity. J Clin Med. 2018;7(10).

78. Koop SM, ten Klooster PM, Vonkeman HE, Steunebrink LM, van de Laar MA. Neuropathic-like pain features and cross-sectional associations in rheumatoid arthritis. Arthritis Res Ther. $2015 ; 17237$.

79. Ryan S, McGuire B. Psychological predictors of pain severity, pain interference, depression, and anxiety in rheumatoid arthritis patients with chronic pain. Br J Health Psychol. 2016;21(2):336-50.

80. Marrie RA, Hitchon CA, Walld R, Patten SB, Bolton JM, Sareen J, et al. Increased burden of psychiatric disorders in rheumatoid arthritis. Arthritis Care Res (Hoboken). 2018;70(7):970-8.

81. Lu MC, Guo HR, Lin MC, Livneh H, Lai NS, Tsai TY. Bidirectional associations between rheumatoid arthritis and depression: a nationwide longitudinal study. Sci Rep. 2016;620647.

82. Alpizar-Rodriguez D, Forger F, Courvoisier DS, Gabay C, Finckh A. Role of reproductive and menopausal factors in functional and structural progression of rheumatoid arthritis: results from the SCQM cohort. Rheumatol (Oxf). 2019;58(3): 432-40.

83. Smolen JS, Landewe R, Bijlsma J, Burmester G, Chatzidionysiou K, Dougados $\mathrm{M}$, et al. EULAR recommendations for the management of rheumatoid arthritis with synthetic and biological diseasemodifying antirheumatic drugs: 2016 update. Ann Rheum Dis. 2017;76(6):960-77.

84. Whittle SL, Colebatch AN, Buchbinder R, Edwards CJ, Adams K, Englbrecht M, et al. Multinational evidence-based recommendations for pain management by pharmacotherapy in inflammatory arthritis: integrating systematic literature research and expert opinion of a broad panel of rheumatologists in the $3 e$ Initiative. Rheumatol (Oxf). 2012;51(8):1416-25.

85. Richards BL, Whittle SL, Buchbinder R. Antidepressants for pain management in rheumatoid arthritis. Cochrane Database Syst Rev. 2011(11): CD008920.

86. Knittle K, Maes S, de Gucht V. Psychological interventions for rheumatoid arthritis: examining the role of self-regulation with a systematic review and meta-analysis of randomized controlled trials. Arthritis Care Res (Hoboken). 2010;62(10):1460-72.

87. Baillet A, Vaillant M, Guinot M, Juvin R, Gaudin P. Efficacy of resistance exercises in rheumatoid 
arthritis: meta-analysis of randomized controlled trials. Rheumatol (Oxf). 2012;51(3):519-27.

88. Bjorklund G, Dadar M, Chirumbolo S, Aaseth J. Fibromyalgia and nutrition: Therapeutic possibilities? Biomed Pharmacother. 2018;103531-8.

89. Marques AP, Santo A, Berssaneti AA, Matsutani LA, Yuan SLK. Prevalence of fibromyalgia: literature review update. Rev Bras Reumatol Engl Ed. 2017;57(4):356-63.

90. Trouvin AP, Perrot S. New concepts of pain. Best Pract Res Clin Rheumatol. 2019;33(3):101415.

91. Heidari F, Afshari M, Moosazadeh M. Prevalence of fibromyalgia in general population and patients, a systematic review and meta-analysis. Rheumatol Int. 2017;37(9):1527-39.

92. Swiecka M, Maslinska M, Kwiatkowska B. Small fiber neuropathy as a part of fibromyalgia or a separate diagnosis? Int J Clin Rheumtol. 2018;13(6):353-9.

93. Maixner W, Fillingim RB, Williams DA, Smith SB, Slade GD. Overlapping chronic pain conditions: implications for diagnosis and classification. J Pain. 2016;17(9 Suppl):T93-107.

94. Caro XJ, Winter EF. the role and importance of small fiber neuropathy in fibromyalgia pain. Curr Pain Headache Rep. 2015;19(12):55.

95. Bazzichi L, Dini M, Rossi A, Corbianco S, De Feo F, Giacomelli C, et al. Muscle modifications in fibromyalgic patients revealed by surface electromyography (SEMG) analysis. BMC Musculoskelet Disord. 2009;1036.

96. Casale R, Sarzi-Puttini P, Atzeni F, Gazzoni M, Buskila D, Rainoldi A. Central motor control failure in fibromyalgia: a surface electromyography study. BMC Musculoskelet Disord. 2009;1078.

97. de Oliveira DL, Hirotsu C, Tufik S, Andersen ML. The interfaces between vitamin $\mathrm{D}$, sleep and pain. J Endocrinol. 2017;234(1):R23-36.

98. Ciregia F, Giacomelli C, Giusti L, Boldrini C, Piga I, Pepe $P$, et al. Putative salivary biomarkers useful to differentiate patients with fibromyalgia. J Proteomics. 2019;19044-54.

99. Wolfe F, Walitt B, Perrot S, Rasker JJ, Hauser W. Fibromyalgia diagnosis and biased assessment: sex, prevalence and bias. PLoS One. 2018;13(9): e0203755.

100. White HD, Robinson TD. A novel use for testosterone to treat central sensitization of chronic pain in fibromyalgia patients. Int Immunopharmacol. 2015;27(2):244-8.
101. Thornton KGS, Robert M. Prevalence of pelvic floor disorders in the fibromyalgia population: a systematic review. J Obstet Gynaecol Can. 2020;42(1): 72-9.

102. Mulak A, Tache Y, Larauche M. Sex hormones in the modulation of irritable bowel syndrome. World J Gastroenterol. 2014;20(10):2433-48.

103. Macfarlane GJ, Kronisch C, Dean LE, Atzeni F, Hauser W, Fluss E, et al. EULAR revised recommendations for the management of fibromyalgia. Ann Rheum Dis. 2017;76(2):318-28.

104. Casale R, Rainoldi A. Fatigue and fibromyalgia syndrome: clinical and neurophysiologic pattern. Best Pract Res Clin Rheumatol. 2011;25(2):241-7.

105. Keskindag B, Karaaziz M. The association between pain and sleep in fibromyalgia. Saudi Med J. 2017;38(5):465-75.

106. Peng X, Robinson RL, Mease P, Kroenke K, Williams DA, Chen $Y$, et al. Long-term evaluation of opioid treatment in fibromyalgia. Clin J Pain. 2015;31(1): 7-13.

107. Mucke M, Phillips T, Radbruch L, Petzke F, Hauser W. Cannabis-based medicines for chronic neuropathic pain in adults. Cochrane Database Syst Rev. 2018;3CD012182.

108. Piper BJ, Beals ML, Abess AT, Nichols SD, Martin MW, Cobb CM, et al. Chronic pain patients' perspectives of medical cannabis. Pain. 2017;158(7): 1373-9.

109. Sagy I, Bar-Lev Schleider L, Abu-Shakra M, Novack V. Safety and efficacy of medical cannabis in fibromyalgia. J Clin Med. 2019;8(6).

110. Sarzi-Puttini P, Ablin J, Trabelsi A, Fitzcharles MA, Marotto D, Hauser W. Cannabinoids in the treatment of rheumatic diseases: pros and cons. Autoimmun Rev. 2019;18(12):102409.

111. Engeler D, Baranowski AP, Berghmans B, Borovicka J, Cottrell AM, Elneil PS, et al. EAU guidelinesChronic pelvic pain 2019: European Association of Urology; 2019.

112. van de Merwe JP, Nordling J, Bouchelouche $P$, Bouchelouche K, Cervigni M, Daha LK, et al. Diagnostic criteria, classification, and nomenclature for painful bladder syndrome/interstitial cystitis: an ESSIC proposal. Eur Urol. 2008;53(1):60-7.

113. Nasta L. The prevalence of bladder pain syndrome/ interstitial cystitis in Italy: The importance of a National Registry. In: Hanno P, Nordling J, Staskin $\mathrm{D}$, Wein A, Wyndaele J, editors. Bladder pain 
syndrome-an evolution. Cham: Springer; 2018. p. 27-32.

114. Berry SH, Elliott MN, Suttorp M, Bogart LM, Stoto MA, Eggers P, et al. Prevalence of symptoms of bladder pain syndrome/interstitial cystitis among adult females in the United States. J Urol. 2011;186(2):540-4.

115. Wu MP, Luo HL, Weng SF, Ho CH, Chancellor MB, Chuang YC. Risk of urinary tract carcinoma among subjects with bladder pain syndrome/interstitial cystitis: a nationwide population-based study. Biomed Res Int. 2018;20187495081.

116. Barry MJ, Link CL, McNaughton-Collins MF, McKinlay JB, Boston Area Community Health I. Overlap of different urological symptom complexes in a racially and ethnically diverse, communitybased population of men and women. BJU Int. 2008;101(1):45-51.

117. Song Y, Zhang W, Xu B, Hao L, Song J. Prevalence and correlates of painful bladder syndrome symptoms in Fuzhou Chinese women. Neurourol Urodyn. 2009;28(1):22-5.

118. Rais-Bahrami S, Friedlander JI, Herati AS, Sadek MA, Ruzimovsky M, Moldwin RM. Symptom profile variability of interstitial cystitis/painful bladder syndrome by age. BJU Int. 2012;109(9):1356-9.

119. Kim HJ. Update on the pathology and diagnosis of interstitial cystitis/bladder pain syndrome: a review. Int Neurourol J. 2016;20(1):13-7.

120. Grover S, Srivastava A, Lee R, Tewari AK, Te AE. Role of inflammation in bladder function and interstitial cystitis. Ther Adv Urol. 2011;3(1):19-33.

121. Ratner V. Mast cell activation syndrome. Transl Androl Urol. 2015;4(5):587-8.

122. Mattox TF. Interstitial cystitis in adolescents and children: a review. J Pediatr Adolesc Gynecol. 2004;17(1):7-11.

123. Birder L, Andersson KE. Urothelial signaling. Physiol Rev. 2013;93(2):653-80.

124. Parsons CL, Lilly JD, Stein P. Epithelial dysfunction in nonbacterial cystitis (interstitial cystitis). J Urol. 1991;145(4):732-5.

125. Keay S, Seillier-Moiseiwitsch F, Zhang CO, Chai TC, Zhang J. Changes in human bladder epithelial cell gene expression associated with interstitial cystitis or antiproliferative factor treatment. Physiol Genom. 2003;14(2):107-15.
126. Keay SK, Birder LA, Chai TC. Evidence for bladder urothelial pathophysiology in functional bladder disorders. Biomed Res Int. 2014;2014865463.

127. Sant GR. Etiology, pathogenesis, and diagnosis of interstitial cystitis. Rev Urol. 2002;4 Suppl 1S9-S15.

128. Van De Merwe JP, Arendsen HJ. Interstitial cystitis: a review of immunological aspects of the aetiology and pathogenesis, with a hypothesis. BJU Int. 2000;85(8):995-9.

129. Zhang QH, Shen XC, Zhou ZS, Chen ZW, Lu GS, Song B. Decreased nanobacteria levels and symptoms of nanobacteria-associated interstitial cystitis/painful bladder syndrome after tetracycline treatment. Int Urogynecol J. 2010;21(1):103-9.

130. Nickel JC, Stephens A, Landis JR, Mullins C, van Bokhoven A, Lucia MS, et al. Assessment of the lower urinary tract microbiota during symptom flare in women with urologic chronic pelvic pain syndrome: A MAPP network study. J Urol. 2016;195(2):356-62.

131. Rosamilia A, Cann L, Scurry J, Rogers P, Dwyer P. Bladder microvasculature and the effects of hydrodistention in interstitial cystitis. Urology. 2001;57(6 Suppl 1):132.

132. Lee JD, Lee MH. Increased expression of hypoxiainducible factor-1alpha and vascular endothelial growth factor associated with glomerulation formation in patients with interstitial cystitis. Urology. 2011;78(4):971 e11-5.

133. Latremoliere A, Woolf CJ. Central sensitization: a generator of pain hypersensitivity by central neural plasticity. J Pain. 2009;10(9):895-926.

134. Woolf CJ, Salter MW. Neuronal plasticity: increasing the gain in pain. Science. 2000;288(5472): 1765-9.

135. Ji RR, Kohno T, Moore KA, Woolf CJ. Central sensitization and LTP: do pain and memory share similar mechanisms? Trends Neurosci. 2003;26(12): 696-705.

136. Chaitow L, Jones R. Chronic pelvic pain and dysfunction. London: Elsevier Health Sciences; 2012.

137. Origoni M, Leone Roberti Maggiore U, Salvatore S, Candiani M. Neurobiological mechanisms of pelvic pain. Biomed Res Int. 2014;2014903848.

138. Malde S, Palmisani S, Al-Kaisy A, Sahai A. Guideline of guidelines: bladder pain syndrome. BJU Int. 2018;122(5):729-43.

139. Warren JW, Brown J, Tracy JK, Langenberg P, Wesselmann U, Greenberg P. Evidence-based criteria for 
pain of interstitial cystitis/painful bladder syndrome in women. Urology. 2008;71(3):444-8.

140. Krieger JN, Stephens AJ, Landis JR, Clemens JQ, Kreder $\mathrm{K}$, Lai $\mathrm{HH}$, et al. Relationship between chronic nonurological associated somatic syndromes and symptom severity in urological chronic pelvic pain syndromes: baseline evaluation of the MAPP study. J Urol. 2015;193(4):1254-62.

141. Lai HH, Jemielita T, Sutcliffe S, Bradley CS, Naliboff B, Williams DA, et al. Characterization of whole body pain in urological chronic pelvic pain syndrome at baseline: A MAPP research network study. J Urol. 2017;198(3):622-31.

142. Kim SH, Oh SA, Oh SJ. Voiding diary might serve as a useful tool to understand differences between bladder pain syndrome/interstitial cystitis and overactive bladder. Int J Urol. 2014;21(2):179-83.

143. Lubeck DP, Whitmore K, Sant GR, Alvarez-Horine S, Lai C. Psychometric validation of the O'leary-Sant interstitial cystitis symptom index in a clinical trial of pentosan polysulfate sodium. Urology. 2001;57(6 Suppl 1):62-6.

144. Acar O, Tarcan T. Cystoscopic evaluation and clinical phenotyping in interstitial cystitis/bladder pain syndrome. J Turk Ger Gynecol Assoc. 2019;20(2): $117-22$.

145. Ens G, Garrido GL. Role of cystoscopy and hydrodistention in the diagnosis of interstitial cystitis/bladder pain syndrome. Transl Androl Urol. 2015;4(6):624-8.

146. Turner KJ, Stewart LH. How do you stretch a bladder? A survey of UK practice, a literature review, and a recommendation of a standard approach. Neurourol Urodyn. 2005;24(1):74-6.

147. Nordling J, Anjum FH, Bade JJ, Bouchelouche K, Bouchelouche P, Cervigni M, et al. Primary evaluation of patients suspected of having interstitial cystitis (IC). Eur Urol. 2004;45(5):662-9.

148. Hanno PM, Burks DA, Clemens JQ, Dmochowski RR, Erickson D, Fitzgerald MP, et al. AUA guideline for the diagnosis and treatment of interstitial cystitis/bladder pain syndrome. J Urol. 2011;185(6): 2162-70.

149. Manheimer E, Cheng K, Wieland LS, Shen X, Lao L, Guo M, et al. Acupuncture for hip osteoarthritis. Cochrane Database Syst Rev. 2018;5CD013010.

150. Buhagiar MA, Naylor JM, Harris IA, Xuan W, Kohler F, Wright R, et al. Effect of inpatient rehabilitation vs a monitored home-based program on mobility in patients with total knee arthroplasty: the HIHO randomized clinical trial. JAMA. 2017;317(10): 1037-46.

151. Coulter ID, Crawford C, Hurwitz EL, Vernon H, Khorsan R, Suttorp Booth M, et al. Manipulation and mobilization for treating chronic low back pain: a systematic review and meta-analysis. Spine J. 2018;18(5):866-79.

152. Rahman A, Underwood M, Carnes D. Fibromyalgia. BMJ. 2014;348-1224.

153. Jimenez-Trujillo I, Lopez-de-Andres A, Del Barrio JL, Hernandez-Barrera V, Valero-de-Bernabe M, Jimenez-Garcia R. Gender differences in the prevalence and characteristics of pain in spain: report from a population-based study. Pain Med. 2019;20(12): 2349-59.

154. Saragiotto BT, Maher CG, Yamato TP, Costa LO, Menezes Costa LC, Ostelo RW, et al. Motor control exercise for chronic non-specific low-back pain. Cochrane Database Syst Rev. 2016(1):CD012004.

155. Shi Z, Zhou H, Lu L, Pan B, Wei Z, Yao X, et al. Aquatic exercises in the treatment of low back pain: a systematic review of the literature and metaanalysis of eight studies. Am J Phys Med Rehabil. 2018;97(2):116-22.

156. Steffens D, Maher CG, Pereira LS, Stevens ML, Oliveira VC, Chapple $M$, et al. Prevention of low back pain: a systematic review and meta-analysis. JAMA Intern Med. 2016;176(2):199-208.

157. Li Y, Su Y, Chen S, Zhang Y, Zhang Z, Liu C, et al. The effects of resistance exercise in patients with knee osteoarthritis: a systematic review and metaanalysis. Clin Rehabil. 2016;30(10):947-59.

158. Bidonde J, Busch AJ, Schachter CL, Webber SC, Musselman KE, Overend TJ, et al. Mixed exercise training for adults with fibromyalgia. Cochrane Database Syst Rev. 2019;5CD013340.

159. Amris K, Waehrens EE, Christensen R, Bliddal H, Danneskiold-Samsoe B, Group IMS. Interdisciplinary rehabilitation of patients with chronic widespread pain: primary endpoint of the randomized, nonblinded, parallel-group IMPROvE trial. Pain. 2014;155(7):1356-64

160. Johnson MI, Claydon LS, Herbison GP, Jones G, Paley CA. Transcutaneous electrical nerve stimulation (TENS) for fibromyalgia in adults. Cochrane Database Syst Rev. 2017;10CD012172.

161. Bidonde J, Busch AJ, van der Spuy I, Tupper S, Kim SY, Boden C. Whole body vibration exercise training for fibromyalgia. Cochrane Database Syst Rev. 2017;9CD011755. 
162. Williams MA, Srikesavan C, Heine PJ, Bruce J, Brosseau L, Hoxey-Thomas N, et al. Exercise for rheumatoid arthritis of the hand. Cochrane Database Syst Rev. 2018;7CD003832.

163. Osteras N, Kjeken I, Smedslund G, Moe RH, Slatkowsky-Christensen B, Uhlig T, et al. Exercise for hand osteoarthritis: a Cochrane systematic review. J Rheumatol. 2017;44(12):1850-8.

164. Armour M, Ee CC, Naidoo D, Ayati Z, Chalmers KJ, Steel KA, et al. Exercise for dysmenorrhoea. Cochrane Database Syst Rev. 2019;9CD004142.

165. Shiri R, Coggon D, Falah-Hassani K. Exercise for the prevention of low back and pelvic girdle pain in pregnancy: a meta-analysis of randomized controlled trials. Eur J Pain. 2018;22(1):19-27.

166. Hershman DL, Unger JM, Greenlee H, Capodice JL, Lew DL, Darke AK, et al. Effect of acupuncture vs sham acupuncture or waitlist control on joint pain related to aromatase inhibitors among women with early-stage breast cancer: a randomized clinical trial. JAMA. 2018;320(2):167-76.

167. Jensen IB, Bergstrom G, Ljungquist $T$, Bodin L, Nygren AL. A randomized controlled component analysis of a behavioral medicine rehabilitation program for chronic spinal pain: are the effects dependent on gender? Pain. 2001;91(1-2):65-78.

168. Waterschoot FP, Dijkstra PU, Hollak N, de Vries HJ, Geertzen JH, Reneman MF. Dose or content? Effectiveness of pain rehabilitation programs for patients with chronic low back pain: a systematic review. Pain. 2014;155(1):179-89.

169. Casale R, Sarzi-Puttini P, Botto R, Alciati A, Batticciotto A, Marotto D, et al. Fibromyalgia and the concept of resilience. Clin Exp Rheumatol. 2019;37 Suppl 116(1):105-13.

170. White B, Driver S, Warren A-M. Considering resilience in the rehabilitation of people with traumatic disabilities. Rehabil Psychol. 2008;53(1):9-17.

171. Playford ED. Beyond standard rehabilitation programmes: Working with people with MS for adequate goal setting and rehabilitation treatment evaluation. Mult Scler. 2019;25(10):1394-401.

172. Racine M, Castarlenas E, de la Vega R, Tome-Pires C, Sole E, Miro J, et al. Sex differences in psychological response to pain in patients with fibromyalgia syndrome. Clin J Pain. 2015;31(5):425-32.

173. Parrish JM, Jenkins NW, Hrynewycz NM, Brundage TS, Singh K. The influence of gender on postoperative PROMIS physical function outcomes following minimally invasive transforaminal lumbar interbody fusion. J Clin Orthop Trauma. 2020;11(5):910-5.

174. Lindgren I, Jonsson AC, Norrving B, Lindgren A. Shoulder pain after stroke: a prospective population-based study. Stroke. 2007;38(2):343-8.

175. Wernicke JF, Pritchett YL, D'Souza DN, Waninger A, Tran P, Iyengar S, et al. A randomized controlled trial of duloxetine in diabetic peripheral neuropathic pain. Neurology. 2006;67(8):1411-20.

176. Goetz CG, Tanner CM, Levy M, Wilson RS, Garron DC. Pain in Parkinson's disease. Mov Disord. 1986;1(1):45-9.

177. Castagna A, Caronni A, Crippa A, Sciume L, Giacobbi G, Corrini C, et al. Sensorimotor perceptive rehabilitation integrated (SPRInt) program: exercises with augmented movement feedback associated to botulinum neurotoxin in idiopathic cervical dystonia-an observational study. Neurol Sci. 2020;41(1):131-8.

178. Farrell MJ, Katz B, Helme RD. The impact of dementia on the pain experience. Pain. 1996;67(1): 7-15.

179. Vargas-Schaffer G. Is the WHO analgesic ladder still valid? Twenty-four years of experience. Can Fam Phys. 2010;56(6):514-7, e202-5.

180. Ventafridda V, Saita L, Ripamonti C, De Conno F. WHO guidelines for the use of analgesics in cancer pain. Int J Tissue React. 1985;7(1):93-6. 